\title{
Effect of a Pharmacist Intervention on Clinically Important Medication Errors after Hospital Discharge: A Randomized Controlled Trial
}

\author{
Sunil Kripalani, MD, MSc ${ }^{1,2}$, Christianne L. Roumie, MD, MPH ${ }^{2,3,4}$, Anuj K. Dalal, MD ${ }^{5,6,7}$, \\ Courtney Cawthon, MPH ${ }^{2}$, Alexandra Businger, BA ${ }^{5}$, Svetlana K. Eden, MSc $^{8}$, Ayumi \\ Shintani, PhD, MPH ${ }^{8}$, Kelly Cunningham Sponsler, MD ${ }^{1}$, L. Jeff Harris, MD ${ }^{4}$, Cecelia \\ Theobald, MD ${ }^{4}$, Robert L. Huang, MD, MPH ${ }^{4}$, Danielle Scheurer, MD, MSc ${ }^{9}$, Susan Hunt, \\ MD ${ }^{10}$, Terry A. Jacobson, MD ${ }^{11}$, Kimberly J. Rask, MD, PhD ${ }^{11,12}$, Viola Vaccarino, MD, \\ PhD $^{11,12}$, Tejal K. Gandhi, MD, MPH ${ }^{5,7}$, David W. Bates, MD, MSc ${ }^{5,7,13}$, Mark V. Williams, \\ MD ${ }^{14}$, Jeffrey L. Schnipper, MD, MPH ${ }^{5,6,7}$, and PILL-CVD study group \\ ${ }^{1}$ Section of Hospital Medicine, Division of General Internal Medicine and Public Health, \\ Department of Medicine, Vanderbilt University, Nashville, TN \\ ${ }^{2}$ Vanderbilt Center for Health Services Research, Vanderbilt University, Nashville, TN \\ ${ }^{3}$ VA Tennessee Valley Geriatric Research Education Clinical Center (GRECC), HSR\&D Targeted \\ Research Enhancement Program for Patient Healthcare Behavior, and Clinical Research Center \\ of Excellence (CRCoE), Nashville, TN \\ ${ }^{4}$ Department of Medicine, Vanderbilt University, Nashville, TN \\ ${ }^{5}$ Brigham and Women's Hospital, Division of General Medicine and Primary Care, Boston, MA \\ ${ }^{6} \mathrm{BWH}$ Hospitalist Service, Boston, MA \\ ${ }^{7}$ Harvard Medical School, Boston, MA \\ ${ }^{8}$ Department of Biostatistics, Vanderbilt University, Nashville, TN \\ ${ }^{9}$ MUSC Hospitalist Program, Department of Medicine, Medical University of South Carolina, \\ Charleston, SC \\ ${ }^{10}$ University of Washington Hospitalist Service, Department of Medicine, Seattle, WA \\ ${ }^{11}$ Department of Medicine, Emory University School of Medicine, Atlanta, GA \\ ${ }^{12}$ Rollins School of Public Health, Emory University, Atlanta, GA \\ ${ }^{13}$ Harvard School of Public Health, Boston, MA
}

\footnotetext{
Corresponding Author: Sunil Kripalani, MD, MSc, 1215 21st Ave S, Suite 6000 Medical Center East, Nashville, TN 37232, phone: 615-936-3525, fax: 615-936-1269, sunil.kripalani@vanderbilt.edu.

Trial Registration: http://clinicaltrials.gov/ct2/show/NCT00632021, NCT00632021

Address for reprint requests: Sunil Kripalani, MD, MSc, Associate Professor, Department of Medicine, Vanderbilt University, 1215 21st Ave S, Suite 6000 Medical Center East, Nashville, TN 37232

DISCLOSURES

Dr. Kripalani is a consultant to and holds equity in PictureRx, LLC, which makes patient education tools to improve medication management. PictureRx did not provide materials or funding for this study. Dr. Schnipper is a consultant to QuantiaMD, for whom he has helped create on-line educational materials for both providers and patients regarding patient safety, including medication safety. The findings of this study are not a part of those materials. Dr. Schnipper has received grant funding from Sanofi Aventis for an investigator-initiated study to design and evaluate an intensive discharge and follow-up intervention in patients with diabetes. The funder has had no role in the design of the study.
} 
${ }^{14}$ Division of Hospital Medicine, Northwestern University Feinberg School of Medicine, Chicago, IL

\section{Abstract}

Background-Clinically important medication errors are common after hospital discharge. They include preventable or ameliorable adverse drug events as well as medication discrepancies or non-adherence with high potential for future harm (potential adverse drug events).

Objective-The Pharmacist Intervention for Low Literacy in Cardiovascular Disease (PILLCVD) study sought to determine the effect of a tailored intervention on the occurrence of clinically important medication errors after hospital discharge.

Design-Randomized controlled trial with concealed allocation and blinded outcome assessors.

Setting-Two tertiary care academic hospitals.

Patients-Adults hospitalized with acute coronary syndromes or acute decompensated heart failure.

Intervention-Pharmacist-assisted medication reconciliation, inpatient pharmacist counseling, low-literacy adherence aids, and individualized telephone follow-up after discharge.

Measurements-The primary outcome was the number of clinically important medication errors per patient during the first 30 days after hospital discharge. Secondary outcomes included preventable or ameliorable adverse drug events, as well as potential adverse drug events.

Results-Among 851 participants, $432(50.8 \%)$ experienced 1 or more clinically important medication errors; $23 \%$ of such errors were judged to be serious, and $2 \%$ life-threatening. Adverse drug events occurred in 258 patients (30.3\%) and potential adverse drug events in 253 (29.7\%). The intervention did not significantly alter the per-patient number of clinically important medication errors (IRR $=0.92 ; 95 \% \mathrm{CI}, 0.77$ to 1.10 ) or adverse drug events (IRR=1.09; CI, 0.86 to 1.39). Intervention patients tended to have fewer potential adverse drug events (IRR $=0.80 ; \mathrm{CI}$, 0.61 to 1.04$)$.

Limitations-The characteristics of the study hospitals and participants may limit generalizability.

Conclusions-Clinically important medication errors were present among half of patients after hospital discharge and were not significantly reduced by a health-literacy sensitive, pharmacistdelivered intervention.

\section{Keywords}

care transitions; health literacy; medication safety

\section{Introduction}

After returning home from te hospital, patients commonly have problems with their medication regimen (1), and many experience adverse outcomes (2). Adverse drug events (ADEs), defined as injury due to a medication (3), affect $11-17 \%$ of patients during the first few weeks after hospital discharge (4-6). Previous research indicates that many of these events could be prevented (preventable $A D E s$ ) (6). Many others are not entirely preventable, but their duration or severity could be reduced (ameliorable ADEs) (6). In addition to ADEs, other medication-related problems may be present after discharge, which have not yet caused injury but which may cause harm in the future if not corrected. These potential ADEs include discrepancies in the patient's medication regimen $(7,8)$ or episodes of non- 
adherence (9), with a high likelihood of potential future harm. Together, preventable or ameliorable ADEs, and potential ADEs, comprise clinically important medication errors, a meaningful target for patient safety interventions.

Certain patients appear to be at higher risk for clinically important medication errors, including the elderly, those with impaired cognitive function or low health literacy (10), or those prescribed numerous or high-risk medications $(11,12)$. Interventions which utilize pharmacists are generally effective in reducing medication errors and adverse events among hospitalized patients (13). Research is needed to determine the extent to which a pharmacistdelivered intervention can reduce clinically important medication errors during the vulnerable period after hospital discharge, particularly in an era where medication reconciliation is the expected standard of care.

The Pharmacist Intervention for Low Literacy in Cardiovascular Disease (PILL-CVD) study was performed to evaluate the effect of a tailored intervention, consisting of pharmacistassisted medication reconciliation, inpatient pharmacist counseling, low-literacy adherence aids, and individualized telephone follow-up, on the number of clinically important medication errors after hospital discharge.

\section{Methods}

\section{Design Overview}

PILL-CVD was a randomized controlled trial performed at 2 academic medical centers in Nashville, TN and Boston, MA. The study methods are described in detail elsewhere (14). Patients were allocated to intervention or usual care in a 1:1 ratio. The Vanderbilt University Institutional Review Board and the Partners Human Research Committee approved the study. Participants provided written informed consent.

\section{Setting and Participants}

Adults admitted to Vanderbilt University Hospital (VUH) or Brigham and Women's Hospital (BWH) for acute coronary syndromes (15) or acute decompensated heart failure (16) were enrolled between May 2008 and September 2009. Patients were excluded if they were being discharged within 3 hours; were too ill to participate; could not communicate in English or Spanish; had active psychosis, bipolar disorder, delirium, or severe dementia; had hearing or vision impairment; did not manage their own medications; were unlikely to be discharged to home; lacked a telephone; or were in police custody.

Upon patient enrollment, research staff collected demographic information, health literacy (short form of the Test of Functional Health Literacy in Adults, s-TOFHLA) (17), cognitive function (Mini-Cog) (18), self-reported medication adherence (Morisky scale) (19), and understanding of the pre-admission medication regimen (Medication Understanding Questionnaire) (20).

\section{Randomization and Interventions}

Participants were randomized to receive usual care or usual care plus the intervention. Randomization was stratified by study site and diagnosis (acute coronary syndromes or heart failure), in permuted blocks of 2 to 6 patients, by a computer program which maintained concealment of allocation. One unblinded research coordinator at each site administered the randomization, contacted study pharmacists who then delivered the intervention to eligible patients, and participated in the individualized telephone follow-up as described below. All investigators, statisticians, and outcome assessors were blinded. 
The intervention consisted of 4 components - pharmacist-assisted medication reconciliation, tailored inpatient counseling by a pharmacist, provision of low-literacy adherence aids, and individualized telephone follow-up after discharge (14). Study pharmacists $(\mathrm{N}=11)$ performed medication reconciliation at the time of enrollment, discharge, and in-hospital transfers. They communicated with the treating physicians to resolve any clinically relevant, unintentional medication discrepancies.

Intervention counseling was sensitive to the patient's health literacy and cognition. It was typically provided during 2 sessions, or during a single session when discharge occurred on the day of enrollment. During the initial meeting, the pharmacist assessed the patient's baseline understanding of medications and prescription labels, barriers to adherence, and social support. The second meeting generally occurred at discharge and included tailored counseling on the discharge medication regimen and the patient's needs as previously identified. The pharmacist focused on changes between the pre-admission and discharge regimen, strategies to promote adherence and minimize side effects, and high-risk medications such as insulin or warfarin. Pharmacists confirmed understanding using "teachback" (21) and provided low-literacy adherence aids including a pill box and illustrated daily medication schedule $(14,22)$.

Within 1 to 4 days after discharge, an unblinded research coordinator called intervention patients and used a structured interview to identify medication-related problems. As needed, pharmacists then called to address any identified issues in collaboration with the treating inpatient and responsible outpatient physicians.

For patients randomized to usual care, the patients' treating physicians and nurses performed medication reconciliation and provided discharge counseling. At each hospital, medication reconciliation was facilitated by electronic records from the hospital and affiliated clinics, as well as internally developed interfaces to construct a pre-admission medication list. At $\mathrm{BWH}$, the program had additional features (such as reminders to complete a pre-admission medication list and integration with order entry) and required providers to continue, stop, or change each pre-admission medication at admission; this application, combined with process redesign, was previously shown to reduce potential ADEs $(8,23)$. Patients assigned to usual care were not routinely provided a pill box, illustrated medication schedule, or telephone follow-up.

\section{Outcomes and Follow-up}

The primary composite outcome was the number of clinically important medication errors per patient within 30 days after hospital discharge. This included 1) preventable or ameliorable ADEs, and 2) potential ADEs due to medication discrepancies or nonadherence. Secondary outcomes included preventable or ameliorable ADEs; potential ADEs due to discrepancies or non-adherence; and preventable or ameliorable ADEs judged to be serious, life-threatening, or fatal.

Outcomes were determined for each participant by 2 independent clinician adjudicators, blinded to treatment assignment. Each adjudicator reviewed all available medical records during the 30 days after discharge and the results of a patient follow-up phone interview conducted by research staff 25-35 days after discharge. This interview included a detailed review of new or worsening symptoms (to detect possible medication adverse effects); discharge medications (to detect possible discrepancies and non-adherence); and health care utilization after discharge. The adjudicators followed a standardized approach based on previously validated methods to ascertain the presence of ADEs and to grade severity, preventability, and ameliorability $(3,11,24,25)$. For each medication discrepancy or episode of non-adherence, adjudicators graded the potential for harm if left uncorrected; if 
the likelihood of potential harm exceeded 50\%, it was counted as a potential ADE. A drug implicated in an ADE was not eligible to be adjudicated as a potential ADE in the same patient. For each ADE and potential ADE, adjudicators categorized the severity as significant, serious, or life-threatening, following rules and examples from an adjudication manual (Appendix).

Disagreements between the independent adjudicators about whether or not a medication was implicated in a study outcome were uncommon (approximately 3\% for ADEs and 5\% for potential ADEs) and occurred with similar frequency at each site. Disagreements were resolved by discussion or, in about $5 \%$ of cases, with assistance from a third adjudicator.

\section{Statistical Analysis}

Initially sample size was calculated based on achieving a $25 \%$ reduction in the percentage of patients who would experience at least 1 clinically important medication error after discharge (13). Assuming a control event rate of $40 \%(3,5,9,26), 80 \%$ power, a of 0.05 , and $15 \%$ loss to follow-up, we planned to enroll 862 patients. Prior to study initiation, we reframed the primary outcome as the number of clinically important medication errors per patient, rather than the percentage of patients with at least 1 clinically important medication error. Using simulations, we determined that with 862 patients we would be able to detect a $30 \%$ reduction in the primary outcome, with $80 \%$ power and a of 0.05 .

Patient characteristics were described and compared between study arms using Wilcoxon Rank-Sum tests for continuous variables and Pearson chi-square tests for categorical variables.

We analyzed outcomes on an intention-to-treat basis, only excluding patients who withdrew consent or died in the hospital and therefore did not enter the period of outcome assessment. In the primary analysis we compared the number of clinically important medication errors by treatment group using unadjusted negative binomial regression $(27,28)$. We report results of between group comparisons as Incidence Rate Ratios (IRR) with 95\% confidence intervals (CI).

We assessed the adjusted effect of the intervention through multivariable analysis using negative binomial regression. Covariates were chosen a priori and included study site; admission diagnosis (acute coronary syndromes, heart failure, or both); patient age (continuous); marital status (married/cohabitating, non-married); insurance type (private, Medicare, Medicaid, or self-pay); health literacy (continuous); cognition (continuous); number of pre-admission prescription medications (continuous); medication understanding (continuous); self-reported adherence (continuous); access to a primary care provider; and hospital admission during the previous year. Non-linearity of the effect of continuous covariates was assessed by inclusion of restricted cubic splines and retained if $p<0.20$. Missing values of health literacy (2.4\%), medication understanding (8\%), and self-reported adherence $(5.2 \%)$ were imputed using multiple imputation by chained equations with 10 iterations $(29,30)$. Similar analyses were performed for the secondary outcomes.

\section{Sensitivity and Subgroup Analyses}

We performed a sensitivity analysis that also adjusted for baseline comorbidities, an analysis that excluded patients who received additional medication assistance after discharge (through another medication management program or discharge to a skilled nursing facility), and an analysis that included only patients who completed a 30-day follow-up call.

Differential effects of the intervention among subgroups of interest were tested by including cross-product terms for interaction in the multivariable model for covariates selected a priori 
(health literacy, number of medications) or post-hoc (cognition, site). We graphically display these results using forest plots.

Findings with a 2 -sided $p$-value $<0.05$ were considered statistically significant. Analyses were performed in statistical language R, version 2.6.0 (http://www.r-project.org/).

\section{Role of the Funding Source}

The study was funded by the National Heart, Lung, and Blood Institute, which had no role in the design or conduct of the study; collection, management, analysis, or interpretation of the data; or preparation, review, or approval of the manuscript.

\section{Results}

Of 6416 patients screened, we enrolled and randomized 862 patients (430 intervention and 432 usual care) (Figure 1). Eleven patients (7 intervention and 4 usual care) withdrew consent or died in the hospital, leaving 851 patients in the intention-to-treat analysis. Outcome data were obtained from available charts for all patients. Thirty-day telephone follow-up was available for $81 \%$ of patients; this did not differ significantly by site or treatment arm.

Participants had a mean age of 60 years and 14 years of education; $41 \%$ were women (Table 1). Ten percent had inadequate and $9 \%$ had marginal health literacy; $12 \%$ had some degree of cognitive impairment. Sixty-one percent were admitted with acute coronary syndromes only, $31 \%$ with acute heart failure only, and $7 \%$ with both diagnoses. Age was slightly higher among intervention patients $(\mathrm{p}=0.023)$.

\section{Primary outcome}

Among 851 participants analyzed, 432 (50.8\%) experienced 1 or more clinically important medication errors during the 30 days after hospital discharge. Among the 777 such errors, $585(75.2 \%)$ were categorized as significant in severity, 178 (22.9\%) were serious, 14 $(1.8 \%)$ were life-threatening, and 0 were fatal (Table 2).

The mean number of clinically important medication errors was similar in the intervention ( 0.87 per-patient) and usual care ( 0.95 per-patient) groups. Although the treatment effect favored the intervention, this difference was not statistically significant (unadjusted IRR $=0.92 ; 95 \% \mathrm{CI}, 0.77$ to 1.10 ). Models with covariate adjustment and multiple imputation for missing predictors produced similar results.

\section{Secondary outcomes}

A total of 353 preventable or ameliorable ADEs occurred among 258 patients (30.3\%). Most ADEs ( $\mathrm{N}=296,83.9 \%)$ were categorized as significant; 48 (13.6\%) were considered serious, 9 (2.5\%) life-threatening, and 0 fatal (Table 2). Approximately $13 \%$ of ADEs ( $\mathrm{N}=46$ ) resulted in an Emergency Department visit and/or hospital readmission. The drug types most commonly implicated in ADEs were cardiovascular agents, diuretics, opioids, lipid-lowering agents, nutrients, hypoglycemics, and anticoagulants (Table 3). Examples are provided in Table 4 and patient-level outcomes in the Appendix Table.

The number of ADEs per patient was similar in the intervention (0.43) and usual care (0.40) groups, as was the number of serious or life-threatening ADEs. The unadjusted and fully adjusted analyses showed no significant treatment effect on ADEs (Table 2).

A total of 424 potential ADEs were found among 253 patients (29.7\%). Approximately half were related to medication discrepancies and half to non-adherence. The most common 
types of discrepancies were omission of a medication (34.5\%), incorrect dose (32.9\%) or frequency (15.9\%), or an additional medication that should not have been on the list $(11.9 \%)$. Forms of non-adherence included missed doses (48.3\%), premature discontinuation of a medication $(18.0 \%)$, failure to fill $(10.0 \%)$ or delays in filling a prescription $(4.7 \%)$, taking a medication less often $(9.0 \%)$ or more often (2.4\%) than prescribed, and taking smaller $(4.3 \%)$ or larger $(2.4 \%)$ doses than prescribed. The potential consequences of discrepancies and non-adherence were rated as significant $(\mathrm{N}=289,68.2 \%)$, serious $(\mathrm{N}=130$, $30.7 \%)$, or life-threatening ( $\mathrm{N}=5,1.2 \%)$ (Table 2). Medication types implicated in potential ADEs and examples are provided in Tables 3 and 4.

Potential ADEs occurred less often among intervention patients ( 0.44 per-patient) than usual care patients ( 0.55 per-patient). The treatment effect favored the intervention in both unadjusted (IRR=0.80; 95\% CI, 0.61 to 1.04 ) and adjusted analyses (adjusted IRR=0.79; $95 \% \mathrm{CI}, 0.61$ to 1.01 ), but was not statistically significant.

\section{Sensitivity and Subgroup Analyses}

Similar treatment effects were seen in sensitivity analyses which adjusted for baseline comorbidities, excluded the 46 patients who received additional medication assistance after discharge, or included only patients who completed a 30-day follow-up call for data collection. (Results available on request.)

In pre-specified subgroup analyses, the intervention tended to have a greater effect among patients with inadequate health literacy (adjusted IRR for clinically important medication errors $=0.68 ; 95 \%$ CI, 0.39 to 1.19) (Figure 2, Panel A). The relationship between number of pre-admission medications and outcomes was non-linear, with an apparent inflection point at 10 medications. Patients with 10 or more pre-admission medications tended to benefit from the intervention (adjusted IRR for clinically important medication errors $=0.80 ; 95 \%$ CI, 0.61 to 1.05$)$. In post-hoc subgroup analyses, the intervention appeared to benefit patients with impaired cognition and patients enrolled at Vanderbilt, particularly by reducing potential ADEs (Figure 2, Panels A-C).

\section{Discussion}

In this randomized controlled trial, we found that clinically important medication errors were very common, affecting $50.8 \%$ of patients during the first 30 days after hospital discharge. Overall, a health literacy-sensitive pharmacist intervention did not significantly reduce clinically important medication errors or ADEs at the study hospitals. Potential ADEs tended to decline, but this effect was not statistically significant. These results highlight the difficulty of improving medication safety during the transition from hospital to home.

In interpreting the results of this negative trial, a key question is the extent to which its findings are generalizable to other settings. Indeed, as hospitals increasingly implement and evaluate programs to improve care transitions, it is critical to understand contextual factors that may affect the results, as examples of both positive $(13,25)$ and negative $(31)$ studies exist. PILL-CVD was performed at 2 academic hospitals that at baseline had resources to support medication reconciliation, including health information technology. This made it more difficult to show an incremental benefit from the PILL-CVD intervention. Indeed, the effect size was smaller than anticipated and smaller than that found in studies conducted in the pre-medication reconciliation era. Even at these 2 relatively similar academic hospitals, we observed a possible difference in treatment effect. Further study is needed to determine whether hospitals with different characteristics, such as less electronic medical record 
support for medication reconciliation or fewer pharmacist resources, see benefit over usual care from this type of intervention.

Another factor affecting generalizability is that the study participants on average were well educated (median 14 years of education), cognitively intact (88\%), and had a relatively low prevalence of inadequate health literacy (10\%), compared to a $26 \%$ prevalence in the medical literature (32). The PILL-CVD intervention, which was designed to accommodate the needs of patients with low health literacy or cognitive impairment, may be more effective among those populations. This too requires further investigation, as the present study was not powered to detect a benefit in these subgroups.

The intervention had no effect on the number of ADEs after discharge. Part of this finding may be artifactual; the adjudication process has some inherent subjectivity. In particular, patients who learn about side effects through the intervention may report symptoms in such a way that they are more likely to be adjudicated as ADEs, thus altering the apparent effect of the intervention (25). Indeed, intervention patients in this study had a greater number of significant (i.e., symptom-only) ADEs. In addition, reduction of preventable or ameliorable ADEs may require different interventions than those evaluated here, such as closer postdischarge monitoring, clinic-based support, or home visits.

Other findings are noteworthy. The observed incidence of preventable or ameliorable ADEs $(30.3 \%)$ is more than double that reported by Forster and colleagues, despite similar adjudication procedures (4-6). Possible explanations include the present study having a slightly longer period of follow-up (30 days vs. a mean of 24 days), more complete electronic health records for review, and more extensive review of outside medical records (5). Moreover, patients in the present study had specific cardiac conditions, as compared with a general medical population (5).

Potential ADEs were also common, affecting $29.7 \%$ of patients overall. Here, potential ADEs were defined as medication discrepancies or non-adherence during the first 30 days after discharge, whereas others have focused on medication discrepancies only and used a 72 hour period of follow-up (7). It is uncertain how elapsed time affects discrepancies. Medication discrepancies that are present immediately after discharge could be resolved as patients visit their outpatient physicians, though the incidence remained high in the present investigation. Different definitions, data collection procedures, and follow-up duration make comparison to other studies difficult.

Certain study limitations were present. First, as noted above, the characteristics of the study hospitals and participants made it more difficult to show incremental benefit and also limit generalizability. Second, the participants had acute cardiovascular conditions; the number of medication-related problems, classes of medications implicated, and efficacy of this type of intervention may differ in other populations. Third, not all patients received the full intervention as intended, although the vast majority did (14).

In conclusion, we found clinically important medication errors commonly occur during the 30 days following a cardiac hospitalization, and we report a much higher incidence than previously shown for preventable or ameliorable ADEs, as well as potential ADEs. A health literacy-sensitive pharmacist intervention that included post-discharge telephone follow-up did not improve medication safety overall. Reducing ADEs and potential ADEs in the postdischarge period is becoming more critical as hospitals have increasing financial penalties tied to readmission rates. Further work is needed to develop and test interventions in this setting, including strategies for higher-risk populations, as well as additional modalities, such as post-discharge medication reconciliation (33) or closer post-discharge surveillance. 


\section{Acknowledgments}

The PILL-CVD study group includes the following:

Investigators: Sunil Kripalani, MD, MSc (PI); Jeffrey L. Schnipper, MD, MPH (BWH site-PI); Christianne L. Roumie, MD, MPH; Anuj K. Dalal, MD; Terry A. Jacobson, MD; Kimberly J. Rask, MD, PhD; Viola Vaccarino, MD, PhD; Tejal K. Gandhi, MD, MPH; and David W. Bates, MD, MSc.

Biostatistics: Ayumi Shintani, PhD; Svetlana K. Eden, MSc; Charles Dupont.

Research staff: Courtney Cawthon, MPH (coordinator); Alexandra Businger (coordinator); Ileko Mugalla, MS, $\mathrm{PhD}$, MPH; Kurt J. Niesner; Abby Myers; Edith Swain; Jeffrey Kemnitz; Harry Reyes Nieva; Alison C. Pietras; Arianne Cordon, MA; Catherine L. Liang, MPH.

Pharmacists: Daniel C. Johnson, PharmD; Erin B. Neal, PharmD; Stephanie A. Labonville, PharmD; Judy Cheng, PharmD, MPH; Heather D. Dell'Orfano, PharmD; Radmila Levinson, PharmD; Beth Anne Filkins, PharmD; Pershank Bamarni, PharmD; Eli Guadalupe, DPh; Jill S. Helmke, DPh, NPh; David F. Gregory, PharmD; Marketa Marvanova, PharmD, PhD.

Outcome assessors: Kelly Cunningham Sponsler, MD; L. Jeff Harris, MD; Cecelia Theobald, MD; Robert L. Huang, MD, MPH; Danielle Scheurer, MD, MSc; Susan Hunt, MD.

External advisors: Mark V. Williams, MD; Daniel J. Cobaugh, PharmD

Grant support:

Funded by R01 HL089755 (NHLBI, Kripalani) and in part by K23 HL077597 (NHLBI, Kripalani), K08 HL072806 (NHLBI, Schnipper), VA Career Development Award 04-342-2 (Roumie), and UL1 RR024975 (NCRR, Bernard).

\section{APPENDIX}

\section{Appendix Table}

Number of patients with at least 1 clinically important medication error, ADE, or potential ADE by treatment assignment.

\begin{tabular}{|c|c|c|c|}
\hline Outcome, N (\%) & Overall $(\mathrm{N}=\mathbf{8 5 1})$ & Usual Care $(\mathrm{N}=428)$ & Intervention $(\mathrm{N}=\mathbf{4 2 3})$ \\
\hline \multicolumn{4}{|c|}{ Clinically important medication errors ${ }^{\dagger}$} \\
\hline$\geq 1$ & $432(50.8)$ & $219(51.2)$ & $213(50.4)$ \\
\hline$\geq 1$ significant & $366(43.0)$ & $181(42.3)$ & $185(43.7)$ \\
\hline$\geq 1$ serious & $132(15.5)$ & $71(16.6)$ & $61(14.4)$ \\
\hline$\geq 1$ life-threatening & $12(1.4)$ & $5(1.2)$ & $7(1.7)$ \\
\hline \multicolumn{4}{|c|}{ Adverse Drug Events (ADEs) } \\
\hline$\geq 1$ & $258(30.3)$ & $125(29.2)$ & $133(31.4)$ \\
\hline$\geq 1$ significant & $223(26.2)$ & $105(24.5)$ & $118(27.9)$ \\
\hline$\geq 1$ serious & $45(5.3)$ & $23(5.4)$ & $22(5.2)$ \\
\hline$\geq 1$ life-threatening & $7(0.8)$ & $3(0.7)$ & $4(0.9)$ \\
\hline \multicolumn{4}{|l|}{ Potential ADEs } \\
\hline$\geq 1$ & $253(29.7)$ & $132(30.8)$ & $121(28.6)$ \\
\hline$\geq 1$ significant & $197(23.1)$ & $102(23.8)$ & $95(22.5)$ \\
\hline$\geq 1$ serious & 95 (11.2) & $52(12.1)$ & $43(10.2)$ \\
\hline$\geq 1$ life-threatening & $5(0.6)$ & $2(0.5)$ & $3(0.7)$ \\
\hline
\end{tabular}




\section{REFERENCES}

1. Cua YM, Kripalani S. Medication use in the transition from hospital to home. Annals of the Academy of Medicine, Singapore. 2008; 37(2):136-41.

2. Kripalani S, Jackson AT, Schnipper JL, Coleman EA. Promoting effective transitions of care at hospital discharge: a review of key issues for hospitalists. Journal of Hospital Medicine. 2007; 2(5): 314-23. [PubMed: 17935242]

3. Bates DW, Cullen DJ, Laird N, Petersen LA, Small SD, Servi D, et al. ADE Prevention Study Group. Incidence of adverse drug events and potential adverse drug events. Implications for prevention. JAMA. 1995; 274(1):29-34. [PubMed: 7791255]

4. Forster AJ, Clark HD, Menard A, Dupuis N, Chernish R, Chandok N, et al. Adverse events among medical patients after discharge from hospital. CMAJ Canadian Medical Association Journal. 2004; 170(3):345-9.

5. Forster AJ, Murff HJ, Peterson JF, Gandhi TK, Bates DW. The incidence and severity of adverse events affecting patients after discharge from the hospital. Ann Intern Med. 2003; 138:161-7. [PubMed: 12558354]

6. Forster AJ, Murff HJ, Peterson JF, Gandhi TK, Bates DW. Adverse drug events occurring following hospital discharge. Journal of General Internal Medicine. 2005; 20:317-23. [PubMed: 15857487]

7. Coleman EA, Smith JD, Raha D, Min SJ. Posthospital medication discrepancies: prevalence and contributing factors. Archives of Internal Medicine. 2005; 165(16):1842-7. [PubMed: 16157827]

8. Schnipper JL, Hamann C, Ndumele CD, Liang CL, Carty MG, Karson AS, et al. Effect of an electronic medication reconciliation application and process redesign on potential adverse drug events: a cluster-randomized trial. Archives of Internal Medicine. 2009; 169(8):771-80. [PubMed: 19398689]

9. Kripalani S, Henderson LE, Jacobson TA, Vaccarino V. Medication use among inner-city patients after hospital discharge: patient reported barriers and solutions. Mayo Clinic Proceedings. 2008; 83(5):529-35. [PubMed: 18452681]

10. Davis TC, Wolf MS, Bass PF III, Thompson JA, Tilson HH, Neuberger M, et al. Literacy and misunderstanding prescription drug labels. Ann Intern Med. 2006; 145(12):887-94. [PubMed: 17135578]

11. Gandhi TK, Weingart SN, Borus J, Seger AC, Peterson J, Burdick E, et al. Adverse drug events in ambulatory care. New England Journal of Medicine. 2003; 348(16):1556-64. [PubMed: 12700376]

12. Rask KJ, Wells KJ, Teitel GS, Hawley JN, Richards C, Gazmararian JA. Can an algorithm for appropriate prescribing predict adverse drug events? American Journal of Managed Care. 2005; 11(3):145-51. [PubMed: 15786853]

13. Kaboli PJ, Hoth AB, McClimon BJ, Schnipper JL. Clinical pharmacists and inpatient medical care: a systematic review. Archives of Internal Medicine. 2006; 166(9):955-64. [PubMed: 16682568]

14. Schnipper JL, Roumie CL, Cawthon C, Businger A, Dalal AK, Mugalla I, et al. The rationale and design of the Pharmacist Intervention for Low Literacy in Cardiovascular Disease (PILL-CVD) study. Circulation: Cardiovascular Quality \& Outcomes. 2010; 3:212-9. [PubMed: 20233982]

15. Anderson JL, Adams CD, Antman EM, Bridges CR, Califf RM, Casey DEJ, et al. ACC/AHA 2007 guidelines for the management of patients with unstable angina/non-ST-elevation myocardial infarction: a report of the American College of Cardiology/American Heart Association Task Force on Practice Guidelines (Writing Committee to Revise the 2002 Guidelines for the Management of Patients With Unstable Angina/Non-ST-Elevation Myocardial Infarction): developed in collaboration with the American College of Emergency Physicians, American College of Physicians, Society for Academic Emergency Medicine, Society for Cardiovascular Angiography and Interventions, and Society of Thoracic Surgeons. J Am Coll Cardiol. 2007; 50:e1-157. [PubMed: 17692738]

16. McKee PA, Castelli WP, McNamara PM, Kannel WB. The natural history of congestive heart failure: the Framingham study. N Engl J Med. 1971; 285(26):1441-6. [PubMed: 5122894]

17. Nurss, JR.; Parker, RM.; Williams, MV.; Baker, DW. Short test of functional health literacy in adults. Peppercorn Books and Press; Snow Camp, NC: 1998. 
18. Borson S, Scanlan JM, Watanabe J, Tu SP, Lessig M. Simplifying detection of cognitive impairment: comparison of the Mini-Cog and Mini-Mental State Examination in a multiethnic sample. Journal of the American Geriatrics Society. 2005; 53(5):871-4. [PubMed: 15877567]

19. Morisky DE, Green LW, Levine DM. Concurrent and predictive validity of a self-reported measure of medication adherence. Med Care. 1986; 24:67-74. [PubMed: 3945130]

20. Marvanova M, Roumie CL, Eden SK, Cawthon C, Schnipper JL, Kripalani S. Health literacy and medication understanding among hospitalized adults. Journal of Hospital Medicine. 2011; 6:48893. [PubMed: 22042745]

21. Schillinger D, Piette J, Grumbach K, Wang F, Wilson C, Daher C, et al. Closing the loop. Physician communication with diabetic patients who have low health literacy. Arch Intern Med. 2003; 163(1):83-90. [PubMed: 12523921]

22. Kripalani S, Robertson R, Love-Ghaffari MH, Henderson LE, Praska J, Strawder A, et al. Development of an illustrated medication schedule as a low-literacy patient education tool. Patient Education and Counseling. 2007; 66(3):368-77. [PubMed: 17344015]

23. Schnipper JL, Hamann C, Karson AS, Carty MG, Liang CL, Bhan I, et al. Assessment of improvements to IT-based medication reconciliation. Journal of Hospital Medicine. 2010; 68(5 (suppl 1):68.

24. Poon EG, Cina JL, Churchill W, Patel N, Featherstone E, Rothschild JM, et al. Medication dispensing errors and potential adverse drug events before and after implementing bar code technology in the pharmacy. Annals of Internal Medicine. 2006; 145(6):426-34. [PubMed: 16983130]

25. Schnipper JL, Kirwin JL, Cotugno MC, Wahlstrom SA, Brown BA, Tarvin E, et al. Role of pharmacist counseling in preventing adverse drug events after hospitalization. Archives of Internal Medicine. 2006; 166(5):565-71. [PubMed: 16534045]

26. Moore C, Wisnivesky J, Williams S, McGinn T. Medical errors related to discontinuity of care from an inpatient to an outpatient setting. J Gen Intern Med. 2003; 18:646-51. [PubMed: 12911647]

27. McCullaho, P.; Nelder, JA. Generalized Linear Models. Second edition. Chapman \& Hall/CRC; 1999.

28. Elhai JD, Calhoun PS, Ford JD. Statistical procedures for analyzing mental health services data. Psychiatry Research. 2008; 160:129-36. [PubMed: 18585790]

29. Little, RJA.; Rubin, DB. Statistical Analysis with Missing Data. John Wiley and Sons; Hoboken, NJ: 2002. p. 85p. 209

30. Van Buuren, S.; Oudshoorn, K. Multivariate Imputation by Chained Equations. TNO Prevention and Health; Leiden, The Netherlands: 2000. Available at http://web.inter.nl.net/users/ S.van.Buuren/mi/docs/Manual.pdf

31. Walker PC, Bernstein SJ, Jones JNT, Piersma J, Kim H-W, Regal RE, et al. Impact of a pharmacist-facilitated hospital discharge program: a quasi-experimental study. Archives of Internal Medicine. 2009; 169(21):2003-10. [PubMed: 19933963]

32. Paasche-Orlow MK, Parker RM, Gazmararian JA, Nielsen-Bohlman LT, Rudd RR. The prevalence of limited health literacy. Journal of General Internal Medicine. 2005; 20(2):175-84. [PubMed: 15836552]

33. Schnipper JL, Liang CL, Hamann C, Karson AS, Palchuk MB, McCarthy PC, et al. Development of a tool within the electronic medical record to facilitate medication reconciliation after hospital discharge. Journal of the American Medical Informatics Association. 2011; 18(3):309-13. [PubMed: 21486889] 


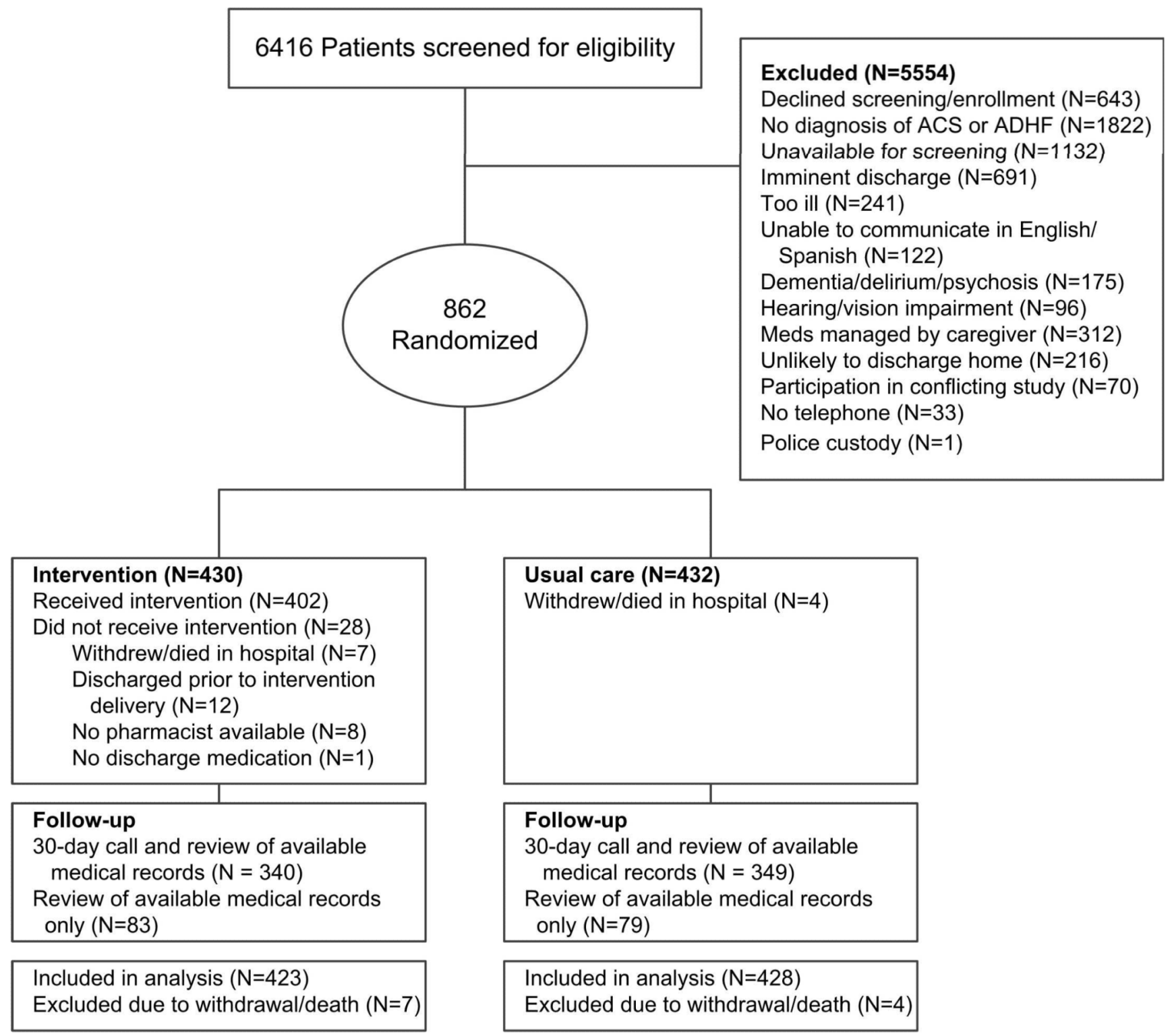

Figure 1.

Flow diagram. 


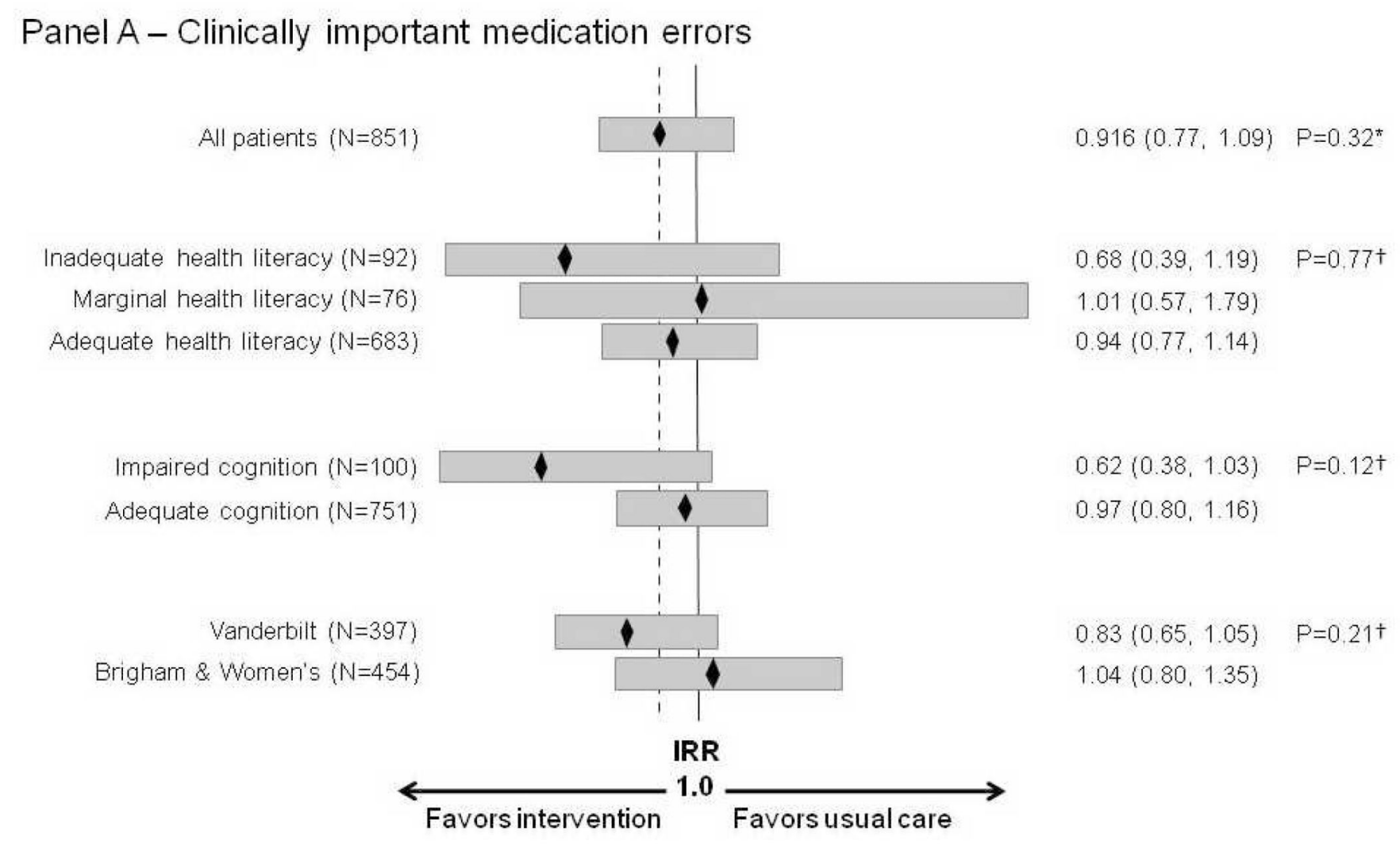

Figure 2.

Adjusted treatment effect on clinically important medication errors, ADEs, and potential ADEs, by subgroups of interest.

Panel A - Clinically important medication errors; Panel B - ADEs; Panel C - Potential ADEs

Incidence Rate Ratios (IRR) are presented. Values $<1$ indicate that the mean count of outcomes in the treatment group is smaller than the mean count in the usual care group. * P-values for the main treatment effect are based on negative binomial regression models, adjusted for covariates, using multiple imputation for missing predictor data. $\dagger$ P-values for the interactions assess homogeneity among subgroup specific treatment effects and are based on the likelihood ratio test comparing models with and without the interaction term. 
Table 1

Patient baseline characteristics

\begin{tabular}{|c|c|c|}
\hline Characteristic & $\begin{array}{c}\text { Usual Care } \\
\quad N=428\end{array}$ & $\begin{array}{c}\text { Intervention } \\
\quad N=423\end{array}$ \\
\hline \multicolumn{3}{|l|}{ Study Hospital } \\
\hline Vanderbilt University Hospital & $200(46.7)$ & 197 (46.6) \\
\hline Brigham and Women's Hospital & $228(53.3)$ & $226(53.4)$ \\
\hline Age, mean (SD) & $59(14)$ & $61(14)$ \\
\hline \multicolumn{3}{|l|}{ Gender } \\
\hline Male & $249(58.2)$ & $250(59.1)$ \\
\hline \multicolumn{3}{|l|}{ Primary language } \\
\hline English & $425(99.3)$ & $414(97.9)$ \\
\hline Spanish & $3(0.7)$ & $9(2.1)$ \\
\hline \multicolumn{3}{|l|}{ Race } \\
\hline White & $335(78.3)$ & $319(75.4)$ \\
\hline Black & $71(16.6)$ & $77(18.2)$ \\
\hline Other & $22(5.1)$ & $27(6.4)$ \\
\hline Education ${ }^{*}$, median years (IQR) & $14(12-16)$ & $14(12-16)$ \\
\hline \multicolumn{3}{|l|}{ Household annual income * } \\
\hline$<10 \mathrm{~K}$ & $17(4.3)$ & $20(5.2)$ \\
\hline $10 \mathrm{~K}$ to $<15 \mathrm{~K}$ & $24(6.1)$ & $21(5.4)$ \\
\hline $15 \mathrm{~K}$ to $<20 \mathrm{~K}$ & $19(4.9)$ & $23(6.0)$ \\
\hline $20 \mathrm{~K}$ to $<25 \mathrm{~K}$ & $47(12.0)$ & $56(14.5)$ \\
\hline $25 \mathrm{~K}$ to $<35 \mathrm{~K}$ & $49(12.5)$ & $49(12.7)$ \\
\hline $35 \mathrm{~K}$ to $<50 \mathrm{~K}$ & $56(14.3)$ & $54(14.0)$ \\
\hline $50 \mathrm{~K}$ to $<75 \mathrm{~K}$ & $60(15.3)$ & $58(15.0)$ \\
\hline $75 \mathrm{~K}+$ & $119(30.4)$ & $105(27.2)$ \\
\hline \multicolumn{3}{|l|}{ Health literacy ${ }^{*}$} \\
\hline Inadequate & $39(9.4)$ & $47(11.4)$ \\
\hline Marginal & $38(9.1)$ & $36(8.7)$ \\
\hline Adequate & $340(81.5)$ & $331(80.0)$ \\
\hline \multicolumn{3}{|l|}{ Cognition * } \\
\hline Impaired & $46(10.8)$ & $52(12.3)$ \\
\hline Has primary care provider & $392(91.6)$ & $386(91.3)$ \\
\hline Pre-admission medications, median (IQR) & $7(4-11)$ & $8(4-11)$ \\
\hline \multicolumn{3}{|l|}{ Comorbidities } \\
\hline Diabetes mellitus & 195 (45.6) & $140(33.1)$ \\
\hline Hypertension & $296(69.2)$ & $306(72.3)$ \\
\hline Hypercholesterolemia & $236(55.1)$ & $234(55.3)$ \\
\hline Coronary artery disease & $211(49.3)$ & $225(53.2)$ \\
\hline Prior myocardial infarction & $73(17.1)$ & $100(23.6)$ \\
\hline Prior stroke or cerebrovascular event & $41(9.6)$ & $30(7.1)$ \\
\hline
\end{tabular}




\begin{tabular}{lcc}
\hline Characteristic & $\begin{array}{c}\text { Usual Care } \\
\boldsymbol{N}=\mathbf{4 2 8}\end{array}$ & $\begin{array}{c}\text { Intervention } \\
\boldsymbol{N = 4 2 3}\end{array}$ \\
\hline Prior coronary revascularization procedure & $195(45.6)$ & $203(48.0)$ \\
\hline
\end{tabular}

Values are given as $\mathrm{N}$ (valid \%) unless noted otherwise.

$\mathrm{SD}=$ Standard Deviation; IQR=Interquartile Range

Missing responses: education $(\mathrm{N}=1)$, cognition $(\mathrm{N}=2)$, income $(\mathrm{N}=74)$, health literacy $(\mathrm{N}=20)$ 


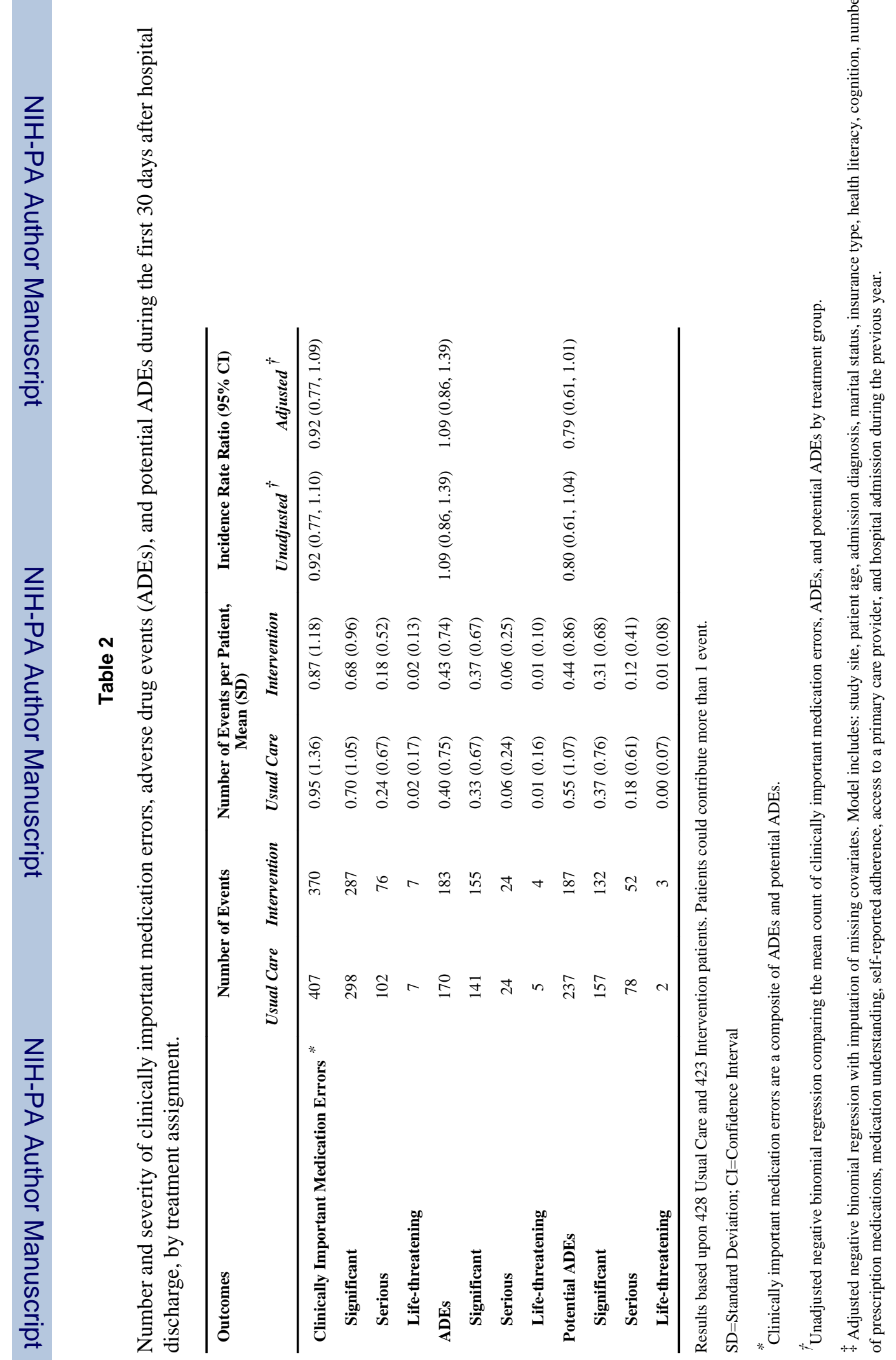


Table 3

Types of medications implicated in ADEs and potential ADEs

\begin{tabular}{lll}
\hline Medication type & ADEs (N=353) & Potential ADEs (N=424) \\
\hline Cardiovascular (excluding diuretics) & $166(47.0)$ & $181(42.7)$ \\
Diuretics & $73(20.7)$ & $52(12.3)$ \\
Opioids & $19(5.4)$ & $0(0)$ \\
Lipid-lowering & $17(4.8)$ & $35(8.3)$ \\
Nutrients (herbs, vitamins, supplements) & $17(4.8)$ & $18(4.2)$ \\
Hypoglycemics & $12(3.4)$ & $35(8.3)$ \\
Anticoagulants & $12(3.4)$ & $7(1.7)$ \\
Antidepressants & $6(1.7)$ & $4(0.9)$ \\
Gastrointestinal & $6(1.7)$ & $11(2.6)$ \\
Steroids & $5(1.4)$ & $3(0.7)$ \\
Sedatives & $3(0.8)$ & $7(1.7)$ \\
Gout & $3(0.8)$ & $6(1.4)$ \\
Thyroid & $3(0.8)$ & $4(0.9)$ \\
Analgesics (non-narcotic) & $3(0.8)$ & $3(0.7)$ \\
Respiratory & $1(0.3)$ & $21(5.0)$ \\
Anti-infectives & $1(0.3)$ & $11(2.6)$ \\
Other & $6(1.7) *$ & $26(6.1)^{\dagger}$ \\
\hline
\end{tabular}

Values are given as $\mathrm{N}(\%)$ and correspond to the number of ADEs and potential ADEs. Patients could contribute more than 1 event.

For ADEs, "Other" includes drugs for incontinence, ophthalmic use, hormone replacement therapy, erectile dysfunction, tobacco cessation, and electrolyte management ( $\mathrm{N}=1$ each).

'For potential ADEs, "Other" includes drugs for ophthalmic use $(\mathrm{N}=6)$, osteoporosis $(\mathrm{N}=4)$, incontinence $(\mathrm{N}=3)$, immunosuppression $(\mathrm{N}=3)$, seizures $(\mathrm{N}=3)$, muscle relaxants $(\mathrm{N}=2)$, Parkinson's $(\mathrm{N}=1)$, erectile dysfunction $(\mathrm{N}=1)$, electrolyte management $(\mathrm{N}=1)$, antipsychotics $(\mathrm{N}=1)$, and antihistamines $(\mathrm{N}=1)$. 
Table 4

Examples of clinically important medication errors

\begin{tabular}{|c|c|c|c|}
\hline Type of Event & $\begin{array}{l}\text { Potential } \\
\text { ADE Type or } \\
\text { ADE } \\
\text { Preventability }\end{array}$ & Severity & Description \\
\hline Potential ADE & $\begin{array}{l}\text { Non- } \\
\text { adherence: } \\
\text { missed doses }\end{array}$ & Significant & $\begin{array}{l}\text { A middle-aged patient with ischemic cardiomyopathy and peripheral vascular disease } \\
\text { complicated by toe } \\
\text { osteomyelitis reported frequent non-adherence (at least } 2 \text { days per week) in the month since } \\
\text { discharge with } \\
\text { aspirin, simvastatin, metoprolol XL, isosrbide dinitrite, and hydralazine secondary to } \\
\text { intermittent nausea } \\
\text { and frustration with taking so many medications. }\end{array}$ \\
\hline Potential ADE & $\begin{array}{l}\text { Non- } \\
\text { adherence: } \\
\text { delay in filling } \\
\operatorname{Rx}\end{array}$ & Serious & $\begin{array}{l}\text { A middle-aged patient was admitted to the hospital with several months of progressive } \\
\text { dyspnea requiring } \\
\text { cardiac bypass surgery complicated by post-operative ischemia. The patient was discharged } \\
\text { on several } \\
\text { cardiac medications including atenolol. In the month after discharge the patient ran out of } \\
\text { atenolol and } \\
\text { delayed refilling the prescription for several days. Given the patient's recent ischemia, the } \\
\text { risk of nonadherence } \\
\text { to atenolol causing recurrent ischemia led the adjudicators to judge this potential ADE as } \\
\text { serious. }\end{array}$ \\
\hline Potential ADE & $\begin{array}{l}\text { Discrepancy: } \\
\text { omission }\end{array}$ & Significant & $\begin{array}{l}\text { An elderly patient with non-ischemic cardiomyopathy was admitted with a } 15 \text { pound weight } \\
\text { gain and } \\
\text { congestive heart failure. Although the patient had been on sublingual nitroglycerin for years, } \\
\text { the patient no } \\
\text { longer had it on the medication list (and was not taking it) } 1 \text { month after discharge because } \\
\text { of a medication } \\
\text { discrepancy. Adjudicators rated this as significant (and not serious) because the } \\
\text { cardiomyopathy was nonischemic } \\
\text { and nitroglycerin was mainly for symptom control. }\end{array}$ \\
\hline Potential ADE & $\begin{array}{l}\text { Discrepancy: } \\
\text { dose }\end{array}$ & Serious & $\begin{array}{l}\text { A middle-aged patient with diabetes mellitus and coronary disease status-post recent } \\
\text { coronary stent } \\
\text { placement was admitted with angina requiring further coronary stenting. The patient was } \\
\text { believed to be on } \\
\text { metformin } 500 \mathrm{mg} \text { twice daily and was prescribed that dose at discharge (in addition to } \\
\text { insulin). At } 1- \\
\text { month follow-up, the patient reporting taking metformin } 1000 \mathrm{mg} \text { twice daily, "which is } \\
\text { what it has always } \\
\text { been." The potential for severe side effects led adjudicators to rate this potential ADE as } \\
\text { serious. }\end{array}$ \\
\hline $\mathrm{ADE}$ & Ameliorable & Significant & $\begin{array}{l}\text { A middle-aged patient was admitted for an ST elevation myocardial infarction requiring bare } \\
\text { metal } \\
\text { coronary stent placement. The hospitalization was complicated by a new diagnosis of atrial } \\
\text { fibrillation. } \\
\text { The patient was discharged on aspirin } 325 \mathrm{mg} \text { daily, clopidogrel for } 6 \text { months, and warfarin. } \\
\text { At } 1 \text {-month } \\
\text { follow-up, the patient reported several weeks of epistaxis, which was finally reported at the } \\
\text { regular PCP } \\
\text { visit; the PCP then decreased the aspirin dose to } 81 \mathrm{mg} \text {. The ADE was adjudicated as } \\
\text { ameliorable because } \\
\text { early PCP notification could have led to a shorter duration of epistaxis. }\end{array}$ \\
\hline $\mathrm{ADE}$ & Preventable & Serious & $\begin{array}{l}\text { An elderly patient with diabetes, chronic kidney disease, coronary artery disease, and } \\
\text { diastolic heart failure } \\
\text { was admitted for unstable angina, heart failure, bradycardia, and hyperkalemia. At 1-month } \\
\text { follow-up, the } \\
\text { patient reported several episodes of symptomatic hypoglycemia. The patient's insulin } \\
\text { requirements in the } \\
\text { hospital had been less than at home. The discharge documentation showed a handwritten } \\
\text { change from } 80 \\
\text { units of } 70 / 30 \text { insulin to } 40 \text { units every morning, but the patient continued to take } 80 \text { units } \\
\text { and often took } \\
\text { the full dose despite not eating. Adjudicators felt that this ADE could have been prevented } \\
\text { with better } \\
\text { documentation and patient education regarding correct dosing and dietary practices. }\end{array}$ \\
\hline
\end{tabular}




\begin{tabular}{llll}
\hline Type of Event & $\begin{array}{l}\text { Potential } \\
\text { ADE Type or } \\
\text { ADE } \\
\text { Preventability }\end{array}$ & Severity & Description \\
\hline ADE & Ameliorable & $\begin{array}{l}\text { Life- } \\
\text { threatening }\end{array}$ & $\begin{array}{l}\text { An elderly patient with coronary artery disease was electively admitted for management of } \\
\text { persistent atrial } \\
\text { flutter and worsening cardiomyopathy. The hospitalization was complicated by intermittent } \\
\text { diplopia found } \\
\text { to be secondary to basilar artery stenosis, for which the patient was managed conservatively } \\
\text { with warfarin } \\
\text { and low-dose aspirin. The patient's first INR check was } 8 \text { days after discharge, and it was } \\
\text { found to be 14.1. } \\
\text { Adjudicators felt that the severity and duration of dangerous over-anticoagulation could have } \\
\text { been } \\
\text { ameliorated with earlier and more frequent monitoring. }\end{array}$ \\
\hline & \\
&
\end{tabular}

$\mathrm{ADE}=$ Adverse Drug Event 